\title{
Clinical Features of COVID-19 Patients in Xiaogan City
}

\author{
Gong Feng ${ }^{1} \cdot$ Wan-Qiang Huang ${ }^{2} \cdot$ Man-Ling Liu ${ }^{1} \cdot$ Si-Ceng Lin ${ }^{1} \cdot$ Xiao-Zhou Zhang ${ }^{2} \cdot$ Yan Zhang ${ }^{3} \cdot$ Xiao-Qing He ${ }^{4}$.

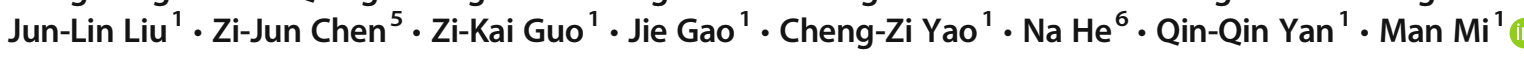

Accepted: 17 August 2020 / Published online: 24 August 2020

(C) Springer Nature Switzerland AG 2020

\begin{abstract}
On February 6, 2020, Xiaogan City became the second most seriously affected city with coronavirus disease 2019 (COVID-19), outside Wuhan district, Hubei Province, China. The objectives are to study the clinical features of COVID-19 patients and assess the relationship between the severity of COVID-19, age, and C-reactive protein (CRP) levels. The retrospective data of 134 COVID-19 patients hospitalized in 3 hospitals of Xiaogan City, between February 1 and March 1, 2020, was collected. This study documented COVID-19 patients. Clinical data in terms of body temperature, history of travel, and direct contact with COVID-19 patients, and incubation period was collected. Out of the 134 patients, only 5 required intensive care. Moreover, 2 patients succumbed during this period. The median age of patients was 45 (3356) years. The most common symptoms at the onset of disease were fever $(66.4 \%)$, cough $(33,6 \%)$, and sore throat $(14.7 \%)$. Amongst the medicines used, antiviral agents $(92.3 \%)$ followed by the traditional Chinese medicine $(89.5 \%)$ were most commonly used. In both the crude and adjusted (I to III) models, odds ratio and its $95 \%$ confidence interval for both age and CRP levels were $>1$. Moreover, the smooth curve fitting graph reflected that the severity of COVID-19 was positively correlated with both age and CRP levels (all $P$ value $<0.05$ ). The signs and symptoms of COVID-19 patients were fairly moderate. The health care professionals treating the COVID-19 patients should be aware of the increased likelihood of progression to severe COVID-19 in elderly patients and those with high CRP levels.
\end{abstract}

Keywords Coronavirus disease $2019 \cdot$ C-reactive protein · Case series

Wan-Qiang Huang, Man-Ling Liu, Si-Ceng Lin, Xiao-Zhou Zhang, Yan Zhang, Xiao-Qing He and Jun-Lin Liu contributed equally to this work.

This article is part of the Topical Collection on Covid-19

$\mathrm{Na} \mathrm{He}$

ylhena@163.com

Qin-Qin Yan

yanqinqin699@163.com

$\triangle$ Man Mi

a17742321665@163.com

1 Xi'an Medical University, Xi'an, China

2 Xiaogan Central Hospital, Xiaogan, China

3 Department of respiratory medicine, Tangdu Hospital Affiliated to Air Force Military Medical University, Xi'an, China

4 Chang'an University, Xi'an, China

5 Pufang Hospital, Chibi, China

6 Department of Gastroenterology, The First Affiliated Hospital of Xi'an Medical University, Xi'an, China

\section{Introduction}

Coronavirus disease 2019 (COVID-19), resulting from an infection with the severe acute respiratory syndrome coronavirus 2 (SARS-CoV-2), has become a serious threat to global public health [1,2]. On February 6, 2020, Xiaogan City became the second most seriously affected city, outside Wuhan, Hubei Province, China, by COVID-19 [3]. The SARS-CoV2 , severe acute respiratory syndrome coronavirus (SARS$\mathrm{CoV}$ ), and Middle East respiratory syndrome coronavirus (MERS-CoV) are responsible for severe and potentially lethal acute respiratory syndromes in humans. Unfortunately, to date, there are no specific/targeted drugs, or vaccines, and the number of SARS-CoV-2-positive patients is growing in various parts of the world.

In spite of the rising number of confirmed cases, the epidemiological studies involving COVID-19 are insufficient, especially those focusing on asymptomatic patients, patients with mild symptoms, or the areas surrounding the COVID19 hotspots [4]. It is worth mentioning that around $30-60 \%$ of COVID-19 patients either are asymptomatic or have mild 
disease, but this does not result in their decreased ability to spread the virus. Thus, these patients may trigger a new wave of COVID-19 outbreak [5]. Moreover, the attention received by the COVID-19 hotspots often exceeds the areas around them, which may result in a surge in the number of patients.

In a study by Lu et al., multivariate Cox regression analysis revealed that the patient's age and $\mathrm{C}$ reactive protein (CRP) levels are independent risk factors for predicting the death [6]. But the studies exploring the relationship between age, CRP levels, and the severity of COVID-19, especially by the means of smooth curve fitting, are lacking. Thus, we describe the clinical characteristics as well as laboratory findings of COVID-19 patients residing in Xiaogan City, so as to have an insight regarding the prevention as well as treatment of COVID-19, and simultaneously explore the relationship between age, CRP levels, and the severity of COVID-19, thereby exploring the indicators for predicting the severity of COVID-19.

\section{Methods}

\section{Data Sources}

This was a retrospective study involving the confirmed COVID-19 cases, diagnosed between February 1 and March 1, 2020, and residing in Xiaogan City. Since the break out of COVID-19, stringent preventive measures were followed in Hubei Province, including the introduction of fever clinics that catered specifically to the suspected COVID-19 patients, defined as the presence of fever, dry cough, or any respiratory signs, and particularly those with a history of travel to Wuhan or direct exposure to confirmed COVID-19 patients within 2 weeks prior to the beginning of disease. A confirmed case of COVID-19 was defined in accordance with the criteria given by the World Health Organization (WHO) [7]. Only the laboratory confirmed COVID-19 patients were included in the study. We gathered the information of 134 laboratory confirmed COVID-19 patients admitted in 3 hospitals of Xiaogan City. The collected data included the dates of disease onset, visits to clinical facilities, and hospital admissions. The incubation period was defined as the duration between direct exposure and the onset of symptoms, estimated amongst the patients providing a reliable date of close contact with confirmed or suspected COVID-19 patients from Wuhan. The epidemiological information was gathered through short interviews involving each patient.

The medical records of patients were fetched and sent out to the data collection center located in Xiaogan. The data was gathered and evaluated by a group of physicians directly involved in the treatment of COVID-19 patients. The data was then entered in a specifically designed case report form. However, if the available information was unclear, the working group in Xiaogan contacted the doctor in-charge and a clarification was obtained. This study was approved by the ethics committee of the Xiaogan Central Hospital in Hubei Province. Written informed consent was obtained from each participant.

\section{Laboratory Confirmation and Treatment}

At admission, sputum specimens and throat swabs were collected from all the patients. The presence of virus was confirmed by subjecting the samples to real-time polymerase chain reaction (rt-PCR) for SARS-CoV-2 RNA within $3 \mathrm{~h}$. rt-PCR was repeated twice every $24 \mathrm{~h}$.

Other laboratory tests included a complete blood count, serum biochemistry, and recognition of other respiratory pathogens including influenza A virus (H1N1, H3N2, H7N9), influenza $\mathrm{B}$ virus, respiratory syncytial virus, and others. The majority of the patients received antiviral treatment. Similarly, many patients received probiotics. Moreover, the patients with resting respiratory rate $>30$ per minute, oxygen saturation $<93 \%$ on room air, or $>50 \%$ progression of illness involving numerous pulmonary lobes on two consecutive days on chest computed tomography (CT) received corticosteroid (40-80 mg/day) and gamma globulin (15-20 g/day) for 3-5 days. Antibiotics such as quinolones and 2ndgeneration beta-lactams were used, if the fever lasted for $>$ 7 days or the levels of CRP were $\geq 30 \mathrm{mg} / \mathrm{L}$ (normal range 0 $8 \mathrm{mg} / \mathrm{L}$ ). COVID-19 patients were considered as cured and subsequently discharged from the hospital, if the outcomes of 2 successive rt-PCR, performed $24 \mathrm{~h}$ apart, were negative.

\section{Logistic Regression Models and Smooth Curve Fitting}

In order to explore the association between age, CRP levels, and severity of COVID-19, we used the methods of multiple regression equation and curve fitting. The multiple regression equation included crude and adjusted (I, II, and III) models and were used to remove the influence of confounding factors and find independent quantitative effect values [8]. In order to intuitively reflect the relationship of disease severity with age and CRP levels, we used the method of smooth curve fitting [9].

\section{Statistical Analysis}

On admission, based on the American Thoracic Society guideline, the study cohort was divided into severe and non-severe cases [10]. The continuous variables were described as either means and standard deviations or medians with interquartile ranges, while the categorical variables were described as percentages. Differences in the laboratory values were assessed by the Student's $t$ test or the Mann-Whitney $U$ test (for normally or not normally distributed continuous variables, respectively). A 
$P$ value of $<0.05$ was considered as statistically significant and analysis was performed by SPSS version 22.0 (SPSS, Chicago, IL, USA) for Windows and R3.3.1 (R Advancement Core Group, http://www.r-project.org).

\section{Result}

\section{Epidemiological Features}

The median age of 134 confirmed COVID-19 patients was 45 (33-56) years. Over half of all the patients were women $(51.5 \%)$. A history of contact with wildlife, recent travel to Wuhan, and close contact with people from Wuhan was observed in $21.1 \%, 39.1 \%$, and $39.1 \%$ of patients, respectively. Moreover, 2 patients were local residents of Wuhan (Table 1).
Amongst the 134 patients, there were only 12 (8.9\%) patients with severe illness, of which $5(3.7 \%)$ received care in intensive care units (ICU) and 2 patients died.

\section{Clinical Characteristics}

Amongst the patients with coexisting conditions, 14 (10.4\%) had hypertension, $12(8.9 \%)$ had diabetes, and only $1(0.7 \%)$ had cerebrovascular disease. The median duration from the beginning of symptoms to hospital admission was $2.0(1.0-4.0)$ days. The most common symptoms reported at the disease onset were fever $(66.4 \%)$, cough $(33.6 \%)$, sore throat $(14.7 \%)$, myalgia or fatigue $(7.0 \%)$, shortness of breath (4.2), nausea and vomiting (2.8), diarrhea (2.1), and chest pain $(0.7 \%)$ (Table 1).
Table 1 Baseline characteristics of COVID-19 patients in Xiaogan City

\begin{tabular}{|c|c|}
\hline Characteristics & $\begin{array}{l}\text { All patients } \\
(n=134)\end{array}$ \\
\hline Median (interquartile), age (years) & $45(33-56)$ \\
\hline \multicolumn{2}{|l|}{ Sex-no. $(\%)$} \\
\hline Male & $65(48.5 \%)$ \\
\hline Female & $69(51.5 \%)$ \\
\hline \multicolumn{2}{|l|}{ Smoking history - no. $(\%)$} \\
\hline Never smokers & $85(63.4 \%)$ \\
\hline Ex-smokers & $20(14.9 \%)$ \\
\hline Current smokers & $29(21.6 \%)$ \\
\hline \multicolumn{2}{|l|}{ Exposure to source of transmission within 14 days-no. (\%) } \\
\hline Local residents of Wuhan & $2(1.7 \%)$ \\
\hline Wildlife & $28(21.1 \%)$ \\
\hline Non local residents: recently been to Wuhan & $52(39.1 \%)$ \\
\hline Non local residents: contacted with people from Wuhan & $52(39.1 \%)$ \\
\hline \multicolumn{2}{|l|}{ Coexisting conditions - no. $(\%)$} \\
\hline Hypertension & $14(10.4 \%)$ \\
\hline Diabetes & $12(9.0 \%)$ \\
\hline Cerebrovascular disease & $1(0.7 \%)$ \\
\hline \multicolumn{2}{|l|}{ Signs and symptoms - no. $(\%)$} \\
\hline Fever & $89(66.4 \%)$ \\
\hline Cough & $48(33.6 \%)$ \\
\hline Shortness of breath & $6(4.2 \%)$ \\
\hline Myalgia or fatigue & $10(7.0 \%)$ \\
\hline Headache & $1(0.7 \%)$ \\
\hline Sore throat & $21(14.7 \%)$ \\
\hline Chest pain & $1(0.7 \%)$ \\
\hline Diarrhea & $3(2.1 \%)$ \\
\hline Nausea and vomiting & $4(2.8 \%)$ \\
\hline Incubation period (days)—no. (\%) & $4(3-5 \%)$ \\
\hline Time from illness onset to first hospital admission (days)—no. (\%) & $2.0(1.0-4.0 \%)$ \\
\hline
\end{tabular}


Table 2 Laboratory and radiographic findings of COVID-19 patients

\begin{tabular}{|c|c|c|c|c|c|c|c|}
\hline & \multirow[b]{2}{*}{$\begin{array}{l}\text { All patients } \\
(n=134)\end{array}$} & \multicolumn{2}{|c|}{$\begin{array}{l}\text { Median }(\mathrm{IQR})(\%) \\
\text { Disease severity }\end{array}$} & \multirow[b]{2}{*}{$P$ value } & \multicolumn{2}{|l|}{$\begin{array}{l}\text { Median }(\mathrm{IQR})(\%) \\
\text { ICU care }\end{array}$} & \multirow[b]{2}{*}{$P$ value } \\
\hline & & $\begin{array}{l}\text { Non-severe } \\
(n=122)\end{array}$ & $\begin{array}{l}\text { Severe } \\
(n=12)\end{array}$ & & $\begin{array}{l}\text { Non-ICU } \\
(n=129)\end{array}$ & $\begin{array}{l}\mathrm{ICU} \\
(n=5)\end{array}$ & \\
\hline \multicolumn{8}{|l|}{ Laboratory findings } \\
\hline White blood cell count $\left(\times 10^{9} / \mathrm{L}\right)$ & $5.0(4.2-6.0)$ & $5.0(4.2-5.9)$ & $5.8(4.2-7.3)$ & 0.002 & $5.0(4.2-6.0)$ & $4.7(3.7-5.1)$ & 0.786 \\
\hline Neutrophil count $\left(\times 10^{9} / \mathrm{L}\right)$ & $3.0(2.5-4.1)$ & $3.0(2.5-3.9)$ & $3.4(2.7-6.8)$ & $<0.001$ & $3.0(2.5-4.0)$ & $3.2(2.6-4.5)$ & 0.767 \\
\hline Lymphocyte count $\left(\times 10^{9} / \mathrm{L}\right)$ & $1.2(0.9-1.7)$ & $1.2(0.9-1.7)$ & $0.8(0.6-1.3)$ & 0.025 & $1.2(0.9-1.7)$ & $0.7(0.5-0.9)$ & 0.02 \\
\hline Platelet count $\left(\times 10^{9} / \mathrm{L}\right)$ & $\begin{array}{l}184.0 \\
\quad(142.0-236.0)\end{array}$ & $\begin{array}{l}184.0 \\
\quad(145.2-236.0)\end{array}$ & $\begin{array}{l}184.0 \\
\quad(124.5-221.8)\end{array}$ & 0.327 & $185.0(145.0-236.0)$ & $\begin{array}{l}148.0 \\
\quad(111.0-201.0)\end{array}$ & 0.359 \\
\hline Hemoglobin $(\mathrm{g} / \mathrm{L})$ & $\begin{array}{l}130.3 \\
\quad(120.7-144.8)\end{array}$ & $\begin{array}{l}130.1 \\
\quad(120.7-143.8)\end{array}$ & $\begin{array}{l}138.0 \\
\quad(120.0-146.5)\end{array}$ & 0.817 & $130.0(120.6-145.0)$ & $\begin{array}{l}139.0 \\
\quad(134.0-142.0)\end{array}$ & 0.938 \\
\hline $\begin{array}{l}\text { Activated partial thromboplastin } \\
\text { time (s) }\end{array}$ & $31.6(28.2-36.4)$ & $31.6(28.3-36.6)$ & $30.6(28.1-33.2)$ & 0.651 & $31.7(28.3-36.5)$ & $29.7(24.5-29.8)$ & 0.172 \\
\hline Prothrombin time (s) & $12.2(10.5-13.7)$ & $11.9(10.4-13.6)$ & $13.4(12.1-14.1)$ & 0.056 & $12.1(10.5-13.7)$ & $12.4(12.3-12.6)$ & 0.399 \\
\hline D-dimer $(\mathrm{mg} / \mathrm{L})$ & $0.3(0.2-0.5)$ & $0.3(0.2-0.5)$ & $0.2(0.1-0.2)$ & 0.378 & $0.3(0.2-0.5)$ & $(61)()(-)$ & \\
\hline Albumin $(\mathrm{g} / \mathrm{L})$ & $40.5(37.8-44.3)$ & $40.9(38.1-44.4)$ & $38.0(35.7-39.0)$ & 0.007 & $40.6(38.0-44.4)$ & $37.4(36.0-38.3)$ & 0.035 \\
\hline Alanine aminotransferase (U/L) & $21.0(11.8-33.0)$ & $21.0(11.5-33.0)$ & $23.5(14.8-31.2)$ & 0.028 & $\begin{array}{l}\text { (128) } 28.5(29.7) 21.0 \\
\quad(11.7-32.2)\end{array}$ & $29.0(22.0-38.0)$ & 0.094 \\
\hline Aspartate aminotransferase (U/L) & $22.0(17.0-31.8)$ & $21.2(17.0-31.0)$ & $30.0(16.0-48.5)$ & $<0.001$ & $21.6(16.9-31.0)$ & $40.0(25.0-62.0)$ & $<0.001$ \\
\hline Sodium $(\mathrm{mmol} / \mathrm{L})$ & $\begin{array}{l}140.2 \\
\quad(138.9-141.6)\end{array}$ & $\begin{array}{l}140.2 \\
\quad(138.9-141.6)\end{array}$ & $\begin{array}{l}139.5 \\
\quad(138.2-141.4)\end{array}$ & 0.001 & $140.2(139.0-141.7)$ & $\begin{array}{l}139.0 \\
\quad(135.6-140.0)\end{array}$ & $<0.001$ \\
\hline Procalcitonin (ng/mL) & $0.1(0.1-0.2)$ & $0.1(0.1-0.2)$ & $0.2(0.1-0.2)$ & 0.154 & $0.1(0.1-0.2)$ & $0.2(0.2-0.2)$ & 0.393 \\
\hline Total bilirubin $(\mathrm{mmol} / \mathrm{L})$ & $11.6(7.9-15.7)$ & $11.6(7.7-15.7)$ & $10.8(8.1-16.5)$ & 0.805 & $11.8(8.0-15.7)$ & $7.9(7.4-8.2)$ & 0.185 \\
\hline Potassium $(\mathrm{mmol} / \mathrm{L})$ & $4.1(3.8-4.4)$ & $4.0(3.8-4.4)$ & $4.3(3.7-4.6)$ & 0.001 & $4.1(3.8-4.4)$ & $4.4(3.7-4.9)$ & $<0.001$ \\
\hline Blood urea nitrogen $(\mathrm{mmol} / \mathrm{L})$ & $4.2(3.3-5.0)$ & $4.0(3.3-4.9)$ & $5.4(4.4-7.0)$ & 0.005 & $4.2(3.3-5.0)$ & $5.3(3.4-6.8)$ & 0.279 \\
\hline Creatine kinase (U/L) & $70.6(45.1-105.6)$ & $70.6(45.1-93.5)$ & $96.0(49.2-178.2)$ & 0.315 & $71.0(45.0-101.4)$ & $65.0(62.0-233.0)$ & 0.648 \\
\hline Fasting glucose (mmol/L) & $5.8(5.2-6.8)$ & $5.8(5.2-6.7)$ & $6.0(5.6-11.5)$ & $<0.001$ & $5.7(5.2-6.7)$ & $6.8(6.1-17.4)$ & $<0.001$ \\
\hline C-reactive protein $(\mathrm{mg} / \mathrm{L})$ & $8.9(1.8-25.4)$ & $7.6(1.6-19.2)$ & $34.0(17.4-69.2)$ & $<0.001$ & $7.9(1.6-22.3)$ & $37.0(34.0-66.3)$ & 0.009 \\
\hline Serum ferritin $(\mu \mathrm{g} / \mathrm{L})$ & $16.3(13.6-20.4)$ & $16.5(13.5-20.4)$ & $14.4(14.4-14.4)$ & 0.736 & $16.3(13.6-20.4)$ & $(53)()(-)$ & \\
\hline Lactate dehydrogenase (U/L) & $\begin{array}{l}192.0 \\
\quad(153.7-237.5)\end{array}$ & $\begin{array}{l}186.5 \\
\quad(152.4-232.2)\end{array}$ & $\begin{array}{l}327.0 \\
\quad(184.8-401.8)\end{array}$ & $<0.001$ & $189.9(153.5-236.0)$ & $\begin{array}{l}464.0 \\
\quad(181.0-498.0)\end{array}$ & 0.001 \\
\hline Creatinine $(\mu \mathrm{mol} / \mathrm{L})$ & $63.2(55.6-80.0)$ & $63.0(55.6-76.7)$ & $75.5(60.0-93.8)$ & 0.172 & $63.0(55.3-76.9)$ & $85.0(81.5-99.0)$ & 0.012 \\
\hline \multicolumn{8}{|l|}{ Radiologic findings } \\
\hline Abnormalities on chest $\mathrm{CT}(\%)$ & $93(69.4)$ & $88(72.1)$ & $10(83.3)$ & $<0.001$ & $90(69.8)$ & $4(80.0)$ & $<0.001$ \\
\hline Ground-glass opacity $(\%)$ & $67(50.0)$ & $58(47.5)$ & $6(50.0)$ & 0.021 & $58(45.0)$ & $3(60.0)$ & 0.042 \\
\hline Local patchy shadowing (\%) & $48(35.8)$ & $41(33.6)$ & $6(50.0)$ & $<0.001$ & $38(30.1)$ & $2(40.0)$ & 0.03 \\
\hline Bilateral patchy shadowing (\%) & $58(43.3)$ & $46(37.7)$ & $9(75.0)$ & $<0.001$ & $46(35.7)$ & $3(60.0)$ & 0.02 \\
\hline Interstitial abnormalities (\%) & $17(12.7)$ & $13(10.7)$ & $3(25.0)$ & $<0.001$ & 15 (11.6) & $1(20.0)$ & $<0.001$ \\
\hline
\end{tabular}

$I Q R$ interquartile range, $I C U$ intensive care units

Table 3 Complications and treatment of COVID-19 patients in Xiaogan City

\begin{tabular}{lc}
\hline Characteristics & All patients $(n=134)$ \\
\hline Complications — no. $(\%)$ & \\
Acute respiratory distress syndrome & $5(3.5)$ \\
Acute kidney injury & $1(0.7)$ \\
Ventilator-associated pneumonia & $2(1.4)$ \\
Arrhythmia & $3(2.1)$ \\
Myocardial injury & $3(2.1)$ \\
Treatment-no. $(\%)$ & \\
Oxygen inhalation & $52(36.4)$ \\
Mechanical ventilation & \\
Invasive & $5(3.5)$ \\
Non-invasive & $3(2.1)$ \\
Administration of intravenous antibiotics & $34(23.8)$ \\
Administration of antifungal medications & $1(0.7)$ \\
Antiviral treatment & $132(92.3)$ \\
Corticosteroid & $3(2.1)$ \\
Immunoglobulin & $16(11.2)$ \\
Chinese medicine treatment & $128(89.5)$ \\
\hline
\end{tabular}

\section{Laboratory and Radiographic Findings in COVID-19 Patients}

In order to explore the relationship between the severity of COVID-19 and CRP, the laboratory data was collected in detail, and the data was then divided into severe and nonsevere group, as well as ICU and non-ICU groups (Table 2).

Compared with non-severe patients, the severe patients had significantly higher median blood levels of white blood cell (WBC) count, neutrophil count, alanine aminotransferase (ALT), aspartate aminotransferase (AST), potassium, blood urea nitrogen (BUN), fasting glucose, CRP, and lactate dehydrogenase (LDH) and significantly lower median blood levels of lymphocyte count, albumin, and sodium (all $P$ values $<0.05$ ).

Similarly, compared with non-ICU patients, ICU patients had significantly higher median blood levels of AST, potassium, fasting glucose, CRP, creatinine, and LDH and 
Table 4 Association between the severity of COVID-19 and age

\begin{tabular}{|c|c|c|c|c|c|c|c|c|}
\hline & $\begin{array}{l}\text { Unadjusted model } \\
\text { OR }(95 \% \mathrm{CI})\end{array}$ & $P$ value & $\begin{array}{l}\text { Adjusted I model } \\
\text { OR }(95 \% \mathrm{CI})\end{array}$ & $P$ value & $\begin{array}{l}\text { Adjusted II model } \\
\text { OR }(95 \% \mathrm{CI})\end{array}$ & $P$ value & $\begin{array}{l}\text { Adjusted III model } \\
\text { OR }(95 \% \mathrm{CI})\end{array}$ & $P$ value \\
\hline Age (year) & $1.060(1.017,1.104)$ & 0.005 & $1.057(1.016,1.100)$ & 0.007 & $1.056(1.005,1.109)$ & 0.031 & $1.065(1.009,1.125)$ & 0.022 \\
\hline
\end{tabular}

Adjust I model adjust for gender; adjust II model adjust for gender, leucocytes, lymphocytes, neutrophils, platelets, and hemoglobin; and adjust III model adjust for gender, leucocytes, lymphocytes, neutrophils, platelets, hemoglobin, sodium ion, and potassium ion

significantly lower median blood levels of lymphocyte count, sodium, and albumin (all $P$ values $<0.05$ ).

Amongst 134 patients who underwent chest CT on admission, the most common patterns were ground-glass opacity $(50.0 \%)$ and bilateral patchy shadows $(43.3 \%)$. Severe patients yielded more prominent radiologic abnormalities on than non-severe patients (all $P$ values $<0.05$ ).

\section{Complications and Treatment}

Amongst all the patients with COVID-19, the most common complications were acute respiratory distress syndrome (ARDS, $2.1 \%$ ), cardiac arrhythmias $(2.1 \%)$, myocardial injury $(2.1 \%)$, ventilator-associated pneumonia (VAP, 1.4), and acute kidney injury $(0.7 \%)$.

Overall, in terms of medication, intravenous antibiotics, antifungal agents, antiviral agents, corticosteroid, immunoglobulin, and Chinese medicine were administered in $23.8 \%$, $0.7 \%, 92.3 \%, 2.1 \%, 11.2 \%$, and $89.5 \%$ respectively.
Simultaneously, oxygen inhalation, invasive, and noninvasive mechanical ventilation were initiated in $36.4 \%$, $3.5 \%$, and $2.1 \%$ patients respectively (Table 3 ).

\section{Relationship of Severity of COVID-19 with Age and CRP Levels}

The relationship between severity of COVID-19 and age was assessed by the methods of multiple regression equation and smooth curve fitting. In the crude mode, the severity of COVID-19 was associated with age (odds ratio $(\mathrm{OR})=$ $1.060,95 \%$ CI 1.017-1.104). Additionally, this relationship was also evident through adjusted I model $(\mathrm{OR}=1.057,95 \%$ CI 1.016-1.100), adjusted II model (OR $=1.056,95 \%$ CI 1.005-1.109), and adjusted III model (OR $=1.065,95 \% \mathrm{CI}$ 1.009-1.125) (Table 4). The smooth curve fitting graph also reflected that the severity of COVID-19 was positively correlated with age (Fig. 1).
Fig. 1 Association between the severities of COVID-19 and age

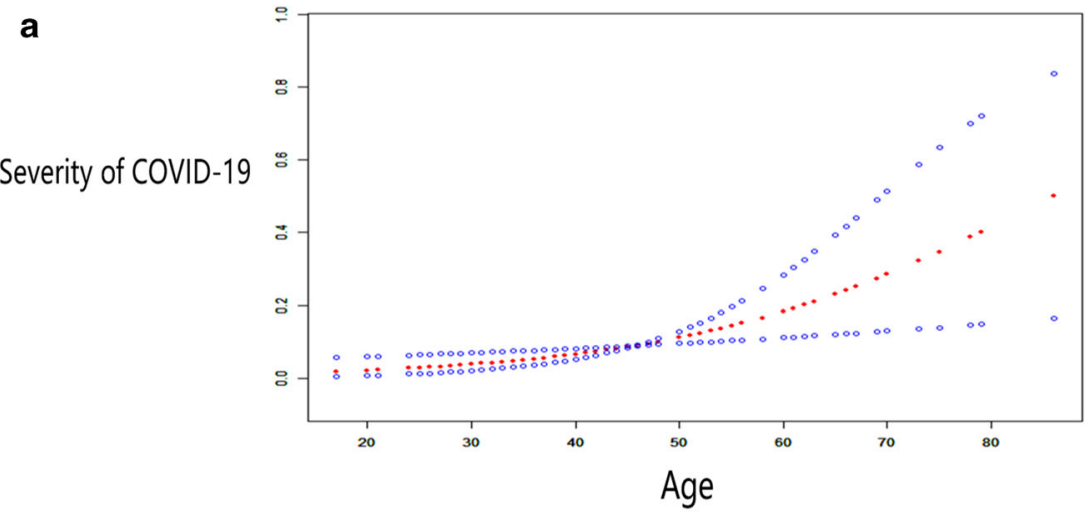

b

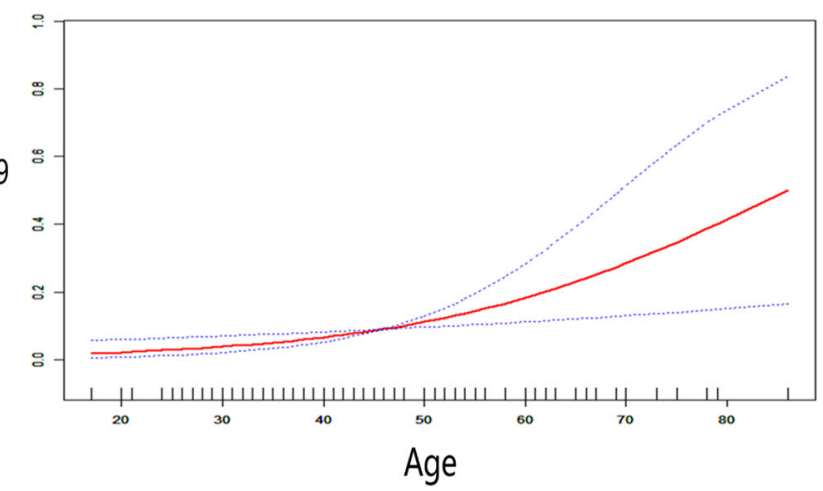


Table 5 Association between the severity of COVID-19 and C-reactive protein

\begin{tabular}{llcccccc}
\hline & $\begin{array}{l}\text { Unadjusted model } \\
\text { OR (95\% CI) }\end{array}$ & $P$ value & $\begin{array}{c}\text { Adjusted I model } \\
\text { OR (95\% CI) }\end{array}$ & $P$ value & $\begin{array}{c}\text { Adjusted II model } \\
\text { OR (95\% CI) }\end{array}$ & $P$ value & $\begin{array}{l}\text { Adjusted III model } \\
\text { OR (95\% CI) }\end{array}$ \\
\hline C-reactive protein (mg/L) & $\begin{array}{c}1.035 \\
(1.013,1.058)\end{array}$ & $<0.001$ & $\begin{array}{c}1.028 \\
(1.004,1.052)\end{array}$ & 0.020 & $\begin{array}{c}1.044 \\
(1.009,1.080)\end{array}$ & $\begin{array}{r}0.012 \\
1.044 \\
(1.006,1.083)\end{array}$ \\
\hline
\end{tabular}

Adjust I model adjust for sex and gender; adjust II model adjust for sex, gender, leucocytes, lymphocytes, neutrophils, platelets, and hemoglobin; and adjust III model adjust for sex, gender, leucocytes, lymphocytes, neutrophils, platelets, hemoglobin, sodium ion, and potassium ion

Similarly, the crude mode revealed an association between the severity of COVID-19 and CRP levels (OR $=1.035,95 \%$ CI 1.013-1.158). Additionally, this relationship was also evident through adjusted I model $(\mathrm{OR}=1.028,95 \%$ CI 1.004 $1.152)$, adjusted II model (OR $=1.044$, 95\% CI 1.009 $1.1080)$, and adjusted III model $(\mathrm{OR}=1.044,95 \% \mathrm{CI}$ 1.006-1.083) (Table 5). The smooth curve fitting graph also reflected that the severity of COVID-19 was positively correlated with CRP levels (Fig. 2).

\section{Discussion}

Compared with the initial COVID-19 patients observed in Wuhan, in terms of disease symptoms and severity, the patients from Xiaogan City, in our study, were relatively moderate, but we could not neglect asymptomatic or mild patients. According to Michael Osterholm, Director of the Center for infectious Disease Research and Policy, University of Minnesota, knowing the proportion of asymptomatic or mild patients is crucial to understand the reasons behind a particular epidemic [5]. A study investigated Japanese citizens $(N=565)$ evacuated from Wuhan in early February. All these individuals were monitored for the symptoms and repeatedly tested for SARS-CoV-2. It was reported that only 13 of the 565 evacuees were infected, of which 4 (31\%) never developed any symptom [11]. A Shanghai Children's Medical Center study involving more than 700 SARS-CoV-2 infected children across the country found that $56 \%$ of the children were asymptomatic or had mild form of COVID-19 [12]. Thus, the only way to prevent the spread of these asymptomatic cases is the use of social isolation measures including closing the schools, cancelling public gatherings, and keeping people at home and away from public places.

In terms of medication, following the antiviral agents, Chinese herbal medicines were most widely used. Amongst the confirmed COVID-19 Chinese patients, $91.5 \%$ used Chinese herbal medicine, of which $90.6 \%$ resided in Hubei Province [13]. Clinical observations have revealed that the cure rate with traditional Chinese medicine (TCM) has reached over $90 \%$ [13]. The TCMs have been found to effectively alleviate the symptoms, contain the progress of the disease, improve the cure rate, reduce the mortality rate, and promote the recovery from COVID-19 $[14,15]$.

As per our analysis, the severity of COVID-19 was found to be positively correlated with the age and CRP levels. Firstly, the CRP levels were significantly elevated amongst the severe patients and those admitted in ICU (all $P$ value < $0.05)$, as compared with non-severe and non-ICU patients, respectively. Secondly, in both the crude and adjusted (I to
Fig. 2 Association between severities of COVID-19 and Creactive protein
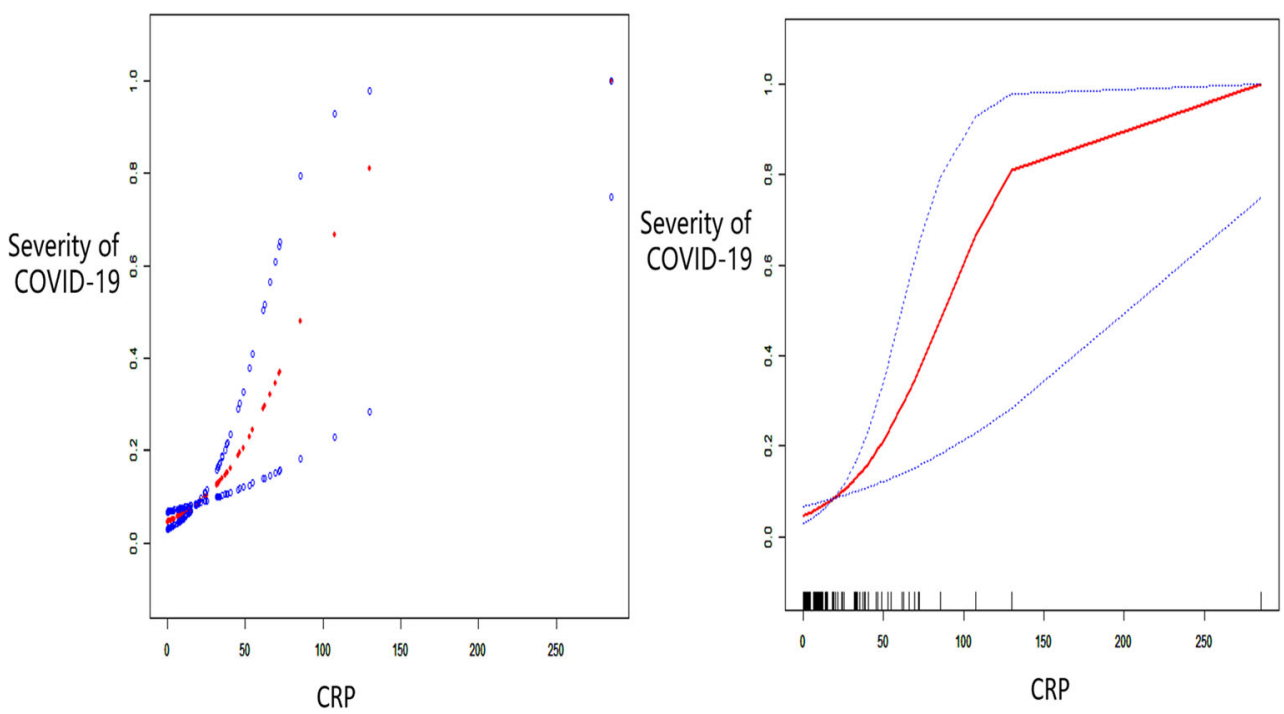
III) models, the value of OR was $>1$ (all $P$ value $<0.05$ ). Finally, as per the smooth curve fitting, the severity of COVID increases with increase in the age and CRP levels (all $P$ value $<0.05$ ).

This study has some limitations. The sample size was insufficient, especially the severe cases. When the data was collected, most of the patients were still hospitalized, so we were unable to estimate either the case fatality rate or the predictors of fatality.

\section{Conclusion}

Compared with the patients primarily infected with SARS$\mathrm{CoV}-2$ in Wuhan, the signs and symptoms of patients in Xiaogan City were fairly moderate. To prevent another wave of COVID-19 outbreaks, these asymptomatic or mild patients should not be ignored. The TCMs were widely used and could play a significant role in the treatment of COVID-19 patients. The severity of COVID-19 was positively correlated with the age and CRP levels. Thus, in clinical practice, to prevent worsening of the disease, the treating physicians should pay special attention to elderly COVID-19 patients and those with high CRP levels.

Funding Information This work was supported by grants from the epidemic prevention and control project of Shaanxi Institute of Higher Education(XGH20043), the Social Science Foundation of Shaanxi Province (2019G017), and Chang'an University graduate student scientific research practice project (300103703068).

Compliance with Ethical Standards This study was approved by the ethics committee of the Xiaogan Central Hospital in Hubei Province. Written informed consent was obtained from each participant.

Conflict of Interest The authors declare that they have no conflicts of interest.

\section{References}

1. Zhu N, Zhang D, Wang W, Li X, Yang B, Song J, et al. A novel coronavirus from patients with pneumonia in China, 2019. N Engl J Med. 2020;382:727-33.

2. Li Q, Guan X, Wu P, Wang X, Zhou L, Tong Y, et al. Early transmission dynamics in Wuhan, China, of novel coronavirusinfected pneumonia. N Engl J Med. 2020;382:1199-207.
3. Wu S, Zheng J, Li Y, Yu H, Shi S, Xie W, et al. A tadiomics nomogram for the preoperative prediction of lymph node metastasis in bladder cancer. Clin Cancer Res. 2017;23:6904-11.

4. Xu XW, Wu XX, Jiang XG, Xu KJ, Ying LJ, Ma CL, et al. Clinical findings in a group of patients infected with the 2019 novel coronavirus (SARS-Cov-2) outside of Wuhan, China: retrospective case series. BMJ. 2020;368:m792.

5. Qiu J. Covert coronavirus infections could be seeding new outbreaks [published online ahead of print, 2020 Mar 20]. Nature. 2020. https://doi.org/10.1038/d41586-020-00822-x.

6. Lu J, Hu S, Fan R. ACP risk grade: a simple mortality index for patients with confirmed or suspected severe acute respiratory syndrome coronavirus 2 disease (COVID-19) during the early stage of outbreak in Wuhan, China (February 20, 2020). Available at SSRN: https://ssrn.com/abstract=3543603 or https://doi.org/10. 2139/ssrn.3543603.

7. Singal AG, Mukherjee A, Elmunzer BJ, Higgins PD, Lok AS, Zhu $\mathrm{J}$, et al. Machine learning algorithms outperform conventional regression models in predicting development of hepatocellular carcinoma. Am J Gastroenterol. 2013;108:1723-30.

8. Fan F, Qi L, Jia J, Xu X, Liu Y, Yang Y, et al. Noninvasive central systolic blood pressure is more strongly related to kidney function decline than peripheral systolic blood pressure in a Chinese community-based population. Hypertension. 2016;67:1166-72.

9. Lyu Y, Shah PS, Ye XY, Warre R, Piedboeuf B, Deshpandey A, et al. Association between admission temperature and mortality and major morbidity in preterm infants born at fewer than 33 weeks' gestation. JAMA Pediatr. 2015;169:e150277.

10. Metlay JP, Waterer GW, Long AC, Anzueto A, Brozek J, Crothers $\mathrm{K}$, et al. Diagnosis and treatment of adults with communityacquired pneumonia. An official clinical practice guideline of the American Thoracic Society and Infectious Diseases Society of America. Am J Respir Crit Care Med. 2019;200:e45-67.

11. Nishiura H, Kobayashi T, Suzuki A, Jung SM, Hayashi K, Kinoshita R, et al. Estimation of the asymptomatic ratio of novel coronavirus infections (COVID-19). Int J Infect Dis. 2020;94:1545 .

12. Dong Y, Mo X, Hu Y, Qi X, Jiang F, Jiang Z, et al. Epidemiological characteristics of 2143 pediatric patients with 2019 coronavirus disease in China. Pediatrics. 2020;145(6):e20200702.

13. Pelusi S, Cespiati A, Rametta R, Pennisi G, Mannisto V, Rosso C, et al. Prevalence and risk factors of significant fibrosis in patients with nonalcoholic fatty liver without steatohepatitis. Clin Gastroenterol Hepatol. 2019;17:2310-9 e2316.

14. Ren JL, Zhang AH, Wang XJ. Traditional Chinese medicine for COVID-19 treatment. Pharmacol Res. 2020;155:104743.

15. Runfeng L, Yunlong H, Jicheng H, Weiqi P, Qinhai M, Yongxia S, et al. Lianhuaqingwen exerts anti-viral and anti-inflammatory activity against novel coronavirus (SARS-CoV-2). Pharmacol Res. 2020;156:104761.

Publisher's Note Springer Nature remains neutral with regard to jurisdictional claims in published maps and institutional affiliations. 